\title{
SPATIAL ASSOCIATION AND OPTIMUM ADJACENT DISTRIBUTION OF TREES IN A MIXED CONIFEROUS- BROADLEAF FOREST IN NORTHEASTERN CHINA
}

\author{
ZHANG, M. T. \\ College of Forestry, Shanxi Agriculture University, Shanxi 030801, P. R. China \\ e-mail:zmt0411@163.com
}

(Received $13^{\text {th }}$ Jan 2017; accepted $23^{\text {rd }}$ Mar 2017)

\begin{abstract}
The spatial patterns and associations of adjacent tree species among the vertical layers of a forest were analysed with point-pattern statistics (a pair-correlation function) in a 1-ha plot. The hierarchy of tree species from highest to lowest importance values (IVs) was as follows: A. nephrolepis, P. jezoensis, P. koraiensis, and T. amurensis. All trees with a diameter at breast height (DBH) $>1.0 \mathrm{~cm}$ were identified. (1) Clustered distributions were observed at fine scales for some tree species, possibly caused by environmental heterogeneity, limited seed dispersal or biological characteristics of seeds; however, random or even regular distributions indicated a "self-thinning" process with intra-specific competition. (2) It was also found positive associations at small scales among species pairs in different tree-height classes that might be a function of the shade-tolerance of congeners, different niches or the influence of habitat heterogeneity on niche breadth, whereas significant negative associations at large scales might be caused by adverse anthropogenic interference or existing habitat heterogeneity. (3) Additionally, habitat heterogeneity, limited seed dispersal and inter-specific competition might be the most important factors that influence species spatial patterns and associations; these scenarios can provide new insight into the development of reforestation practices in forest management.
\end{abstract}

Keywords: spatial pattern; pair-correlation function; scales; importance value; habitat heterogeneity

\section{Introduction}

The regeneration of trees is a crucial process in forest development and forest management. Regeneration proceeds from seed germination to the establishment of young individuals and further growth (Brokaw and Busing, 2000). Regeneration determines tree composition in a forest and further influences the future structure of a forest stand. Therefore, successful long-term management demands careful consideration of all related factors (Feeley et al., 2011; Schweitzer and Dey, 2011; Lochhead and Comeau, 2012). However, many disturbances of natural forests, notably those of anthropogenic origin, have significant negative effects on both the quality and quantity of a typical regeneration (Garbarino et al., 2009; Gourlet-Fleury et al., 2013). As a result, a forest may be in poor condition, with a significant decrease in productivity. Thus, complementary artificial aids for tree regeneration have emerged in response to future forest development (Gagnon et al., 2003; Wagner et al., 2010; Gonzalez-Rodriguez et al., 2011).

Among many alternatives, assigning juveniles in the understory of adult trees may be a priority. Rather than viewing regeneration as a natural scenario of restoration in forests, many artificial supplements to tree regeneration in manipulating reforestation 
focus on the establishment of plantations (Lockhart et al., 2003; Gonzalez-Rodriguez et al., 2011). For example, González-Rodriguez et al. (2011) used two artificial regeneration procedures (direct seeding and planting) to analyze the morphology, growth and survival of two Quercus species. The authors demonstrated that individuals of different ages had diverse growth responses, which suggested that artificial regeneration should have a particular restoration goal that considers the limited dispersal abilities of species. Lockhart et al. (2003) tested the effects of the site preparation method on the artificial regeneration of three oak species and found that some degree of site preparation was necessary for oak seedling establishment, but differences among site preparation treatments were not significant. Many similar studies focused on relationships between species and environmental factors, but the descriptions were largely qualitative. The traits of tree species relevant to the concept of ecological restoration in forestry have, however, not been comprehensively considered.

The spatial patterns, notably those in the vertical direction, and species associations of trees are of particular importance in forest ecosystem research (Condit et al., 2000). These patterns and associations are important in the analyses of tree regeneration and are affected by intra- and inter-specific competitions, seed dispersal, and disturbance (Nguyen et al., 2015; Velázquez et al., 2015). Moreover, analyses of these factors could provide a better understanding of the ecological mechanisms that underlie the dynamics and the processes of forest regeneration (Stoyan and Penttinen, 2000; Zhang, 2004; Hao et al., 2007; Saiz et al., 2014). Our premise in the present study was that optimal tree arrangements might be an evolutionary process in natural forests that can be identified through analyses of spatial tree patterns and associations. Therefore, we assumed the following: (i) in a mixed coniferous-broadleaf forest, at the fine or coarse scale, particular understory species can (or cannot) grow well beneath the canopies of overstory tree species, and (ii) the similarity between spatial distributions and associations in the vertical layers of a forest should be measurable.

In this study, we analysed spatial patterns and associations of tree species in three vertical layers in a 1-ha research plot of a mixed coniferous-broadleaf forest. Our aim was to identify the optimum juxtapositions of different vertical layers of the tree species. We used height as a measure of vertical layering because it is more sensitive for monitoring ecological processes than other parameters that represent the life histories of trees (Chen and Bradshaw, 1999; Salas et al., 2006). Our objectives were to (i) understand the mechanisms of species interactions by determining species spatial patterns and associations among juveniles, lower-height classes and upper-height classes of trees and (ii) determine the dependent relationships and species richness in the vertical layers of the forest. 


\section{Materials and methods}

\section{Study area}

The study site was randomly selected within the mixed coniferous-broadleaf forest of the Jin Gouling Forest, Wangqing, northeastern China $\left(43^{\circ} 22^{\prime} \mathrm{N}, 130^{\circ} 10^{\prime}\right.$ E) (Lei et al., 2007). The landscape is hilly, with forests at altitudes between 300 and $1200 \mathrm{~m}$. The mean monthly temperature is $3.9^{\circ} \mathrm{C}$, and the cumulative temperature above $10^{\circ} \mathrm{C}$ is approximately $2473^{\circ} \mathrm{C}$. The annual precipitation is $500-600 \mathrm{~mm}$, and the annual number of frost-free days is 110-130 d. The region has 170 days of snowfall from November to April (Li et al., 2013; Zhang et al., 2015). The soil is brown podzol. The mean age of the overstory trees in the forest is 70 years old.

\section{Plot establishment and data collection}

We established a $100 \times 100-\mathrm{m}$ plot in an unevenly aged mixed spruce-fir forest. The plot was divided into 25 subplots of $20 \times 20 \mathrm{~m}$. In each subplot, we measured the spatial coordinates ( $\mathrm{x}$ and $\mathrm{y}$ ), the $\mathrm{DBH}$, and the heights $(\mathrm{H})$ of freestanding trees with a $\mathrm{DBH}$ $>1.0 \mathrm{~cm}$. For individuals with $0.3-1.3 \mathrm{~m}$ heights, we measured the tree heights only. The individuals were identified by their scientific species names, and all related parameters were recorded.

\section{Data analyses}

Determining the dominant species in the mixed coniferous-broadleafforest

The dominant species were determined according to the IV, which is a comprehensive quantitative indicator. This parameter can generally characterize the status and role of each species in a community ( $\mathrm{Li}, 2010)$. A larger IV of a given tree species corresponds to a greater dominance in a plot (Hao et al., 2007; Zhao et al., 2012).

The formulas for the IV and other indexes are described as follows:

$$
\text { Relative density }=\left(\frac{\text { Number of individuals of the species }}{\text { Total number of individuals }}\right) \times 100
$$

$$
\text { Relative frequency }=\left(\frac{\text { Frequency of the species }}{\text { Sum of frequencies of all species }}\right) \times 100
$$

$$
\text { Relative dominance }=\left(\frac{\text { Total basal area of the species }}{\text { Total basal area of all species }}\right) \times 100
$$

\section{Analysis of spatial patterns and associations of trees in the forest}

Ripley's $K$ function is widely used in analysing forest spatial structures and is a function that weighs the number of individual plants in a circle of radius $r$ around a 
central arbitrary point (Ripley, 1981; Fajardo et al., 2006; Salas et al., 2006). However, Ripley's $K$ function provides information for a range of distances. Thus, as the radius increases, small-scale information is included in the larger scales; this accumulation confounds the effects between large and small scales. To overcome this disadvantage of Ripley's $K$ function, the pair-correlation function $\mathrm{g}(r)$ is used (Strimbu et al., 2017). Furthermore, $\mathrm{g}(r)$ characterizes patterns based on the frequency of points that co-occur at a given distance $r$ to easily analyze the spatial patterns and associations of forest ecological processes (Wiegand and Moloney, 2004; Wiegand et al., 2007a). Similar to Ripley's $K$ function, $\mathrm{g}(r)$ includes univariate and bivariate statistics. A univariate statistic is used to analyse the distribution of dominant tree species within different vertical layers, and the intra- and inter-species correlations are examined with a bivariate statistic. For a univariate point pattern, if $\mathrm{g}(r)$ is above the upper (or below the lower) limit of the confidence envelope at a given distance $r$, then the patterns are aggregated (or regular); for a bivariate point pattern, these situations explain positive (or negative) interactions.

With the pair-correlation function, applying an inappropriate null model may lead to misinterpretation of spatial patterns caused by differences in spatial heterogeneity and plant propagation characteristics. Heterogeneous Poisson null models, which account for possible environmental heterogeneity, were used in the analysis. Based on the procedure, the points are independent, but the trend of the distribution varied by point location. The specific details were described by Wiegand et al. (2007a). For the univariate statistic, we randomized the locations of the three height layers to analyze the spatial patterns. However, for the bivariate statistic, we assumed that the trees in the tall height classes suppressed the recruitment and growth of individuals in lower layers, whereas trees in lower layers did not affect those in higher layers (Wiegand et al., 2007b). Thus, to analyze the spatial association, we fixed the locations of the upper-layer tree-height classes and randomized the locations of the juvenile and lower tree-height classes. Monte Carlo simulations (499 randomizations) were used to provide 99\% confidence limits. Additionally, a goodness-of-fit (GoF) test was used to avoid expected rates of type I error. We selected a scale interval of 0-20 m and a ring width of $4 \mathrm{~m}$. The software package 'spatstat' in R v. 2.14.0 (R Core Development Team [2012]) was used to map distributions of species, and Programita software [2008] was used to compute pair-correlation functions (Wiegand and Moloney, 2004).

\section{Results}

\section{Spatial structure of tree stands}

We present descriptive statistics for the species found in the 1-ha plot in Table 1. According to importance values (IVs), A. nephrolepis had the highest density and largest basal area. $P$. jezoensis had the second highest density and basal area. Despite the relatively small number of $P$. koraiensis individuals (278), this species ranked third according to the IVs because the mature trees outnumbered those of T. amurensis. $T$. 
amurensis trees had the largest diameter at breast height (DBH) and ranked fourth. These four tree species (i.e., A. nephrolepis, P. jezoensis, P. koraiensis, and T. amurensis) accounted for $88.78 \%$ of the total IV and dominated the stand.

Table 1. Basic characteristics of tree species in a 1-ha mixed coniferous-broadleaf forest plot

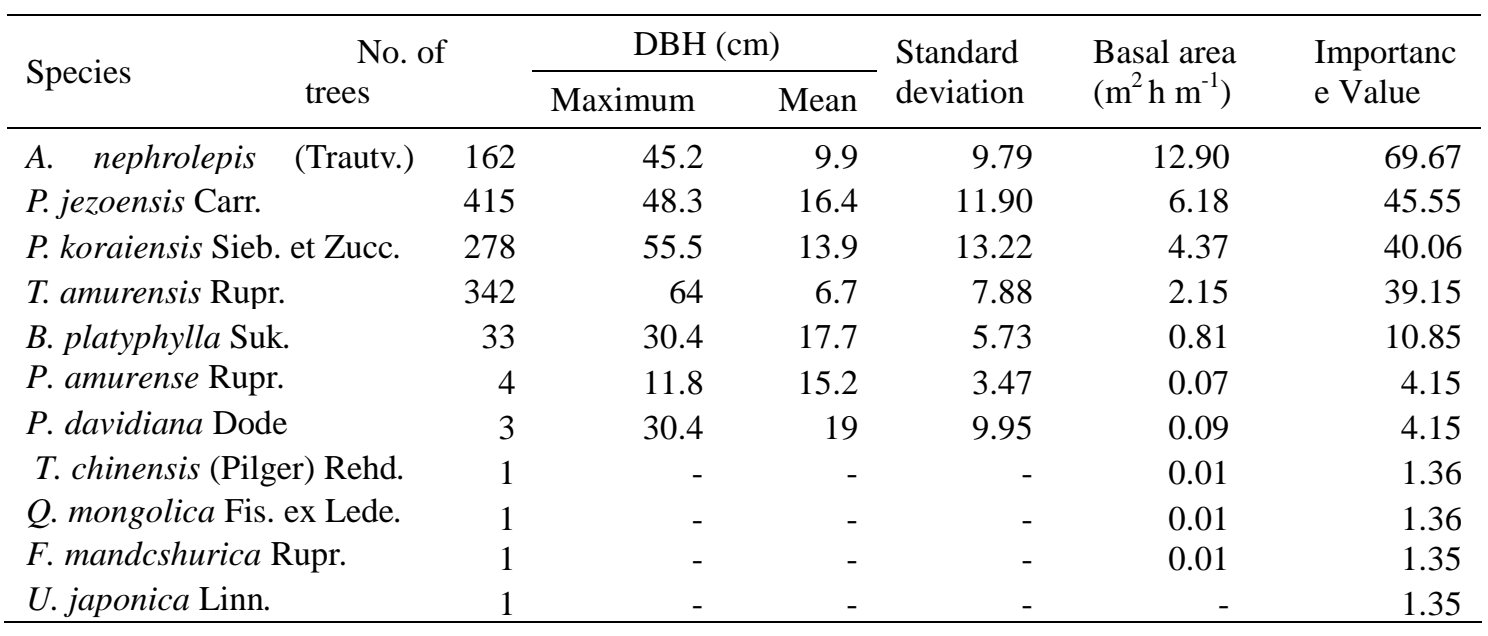

The spatial associations and patterns were analyzed among the different height classes of the dominant tree species (Table 2). Most species were juveniles, with a few individuals in the other categories. Therefore, the tree height was categorized into three classes: juvenile layer $(\mathrm{J})(\mathrm{h}<5 \mathrm{~m})$; lower layer $(\mathrm{L})(5 \mathrm{~m} \leq \mathrm{h}<10 \mathrm{~m})$; and upper layer (U) $(\mathrm{h} \geq 10 \mathrm{~m})$. The members of the classes ( $\mathrm{J}, \mathrm{L}$ and $\mathrm{U}$ ) for individual species were also considered together $(\mathrm{A})$.

Table 2. Basic tree-height characteristics of the four dominant tree species in three height classes

\begin{tabular}{|c|c|c|c|c|c|c|c|}
\hline \multirow{2}{*}{ Species } & \multicolumn{3}{|c|}{ Height $(\mathrm{m})$} & \multicolumn{3}{|c|}{ Numbers of different height classes } & \multirow{2}{*}{ Total } \\
\hline & Maximum & Minimum & Mean & $\mathrm{J}$ & $\mathrm{L}$ & $\mathrm{U}$ & \\
\hline A. nephrolepis & 21.9 & 0.3 & 4.58 & 1185 & 142 & 311 & 1638 \\
\hline P. jezoensis & 24.4 & 0.6 & 5.7 & 265 & 101 & 89 & 415 \\
\hline P. koraiensis & 21.0 & 0.3 & 5.17 & 175 & 50 & 53 & 278 \\
\hline T. amurensis & 19.2 & 0.4 & 4.92 & 224 & 62 & 56 & 342 \\
\hline
\end{tabular}

$\mathrm{J}$, juvenile height class $(\mathrm{h}<5 \mathrm{~m}) ; \mathrm{L}$, lower height class $(5 \mathrm{~m} \leq \mathrm{h}<10 \mathrm{~m})$; and $\mathrm{U}$, upper height class $(\mathrm{h} \geq 10 \mathrm{~m})$

\section{Spatial point-pattern statistics of dominant tree species in different tree-height layers}

The spatial distributions of the four species varied among the different vertical layers (Fig. 1). Visual observations indicated that A. nephrolepis individuals in the juvenile height class might be fascicular in many subplots; however, with an increase in the tree-height layer, random or regular distributions were found. The juveniles of $P$. 
jezoensis and $P$. koraiensis were aggregated at the corners, with fewer juveniles in the centre of the plot. Additionally, many individuals of $P$. koraiensis in the lower and upper tree-height layers were also distributed in ambient subplots. T. amurensis juveniles might be randomly distributed in many subplots. Compared with juvenile individuals, the lower- and upper-layer trees exhibited much more random and regular distributions.

(a) A. nephrolepis

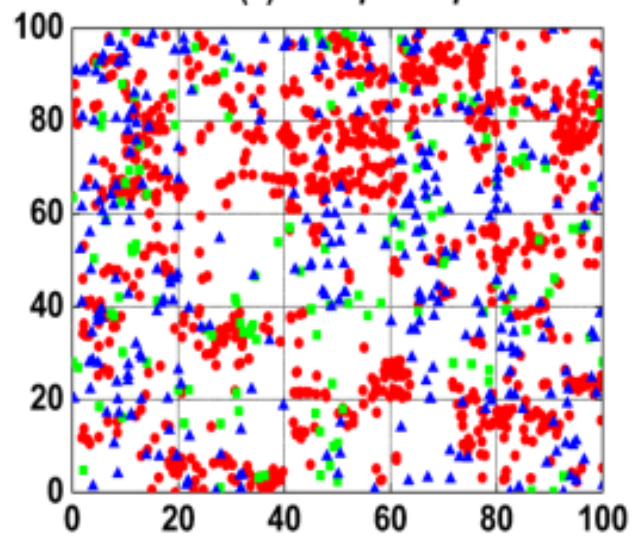

(c) P. koraiensis

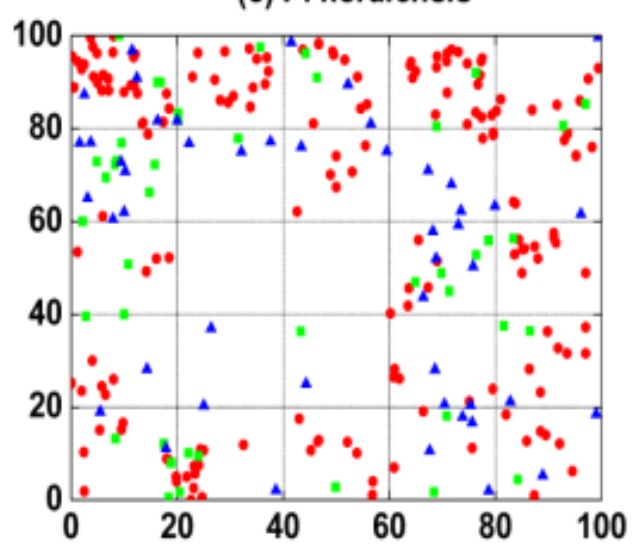

(b) $P$. jezoensis

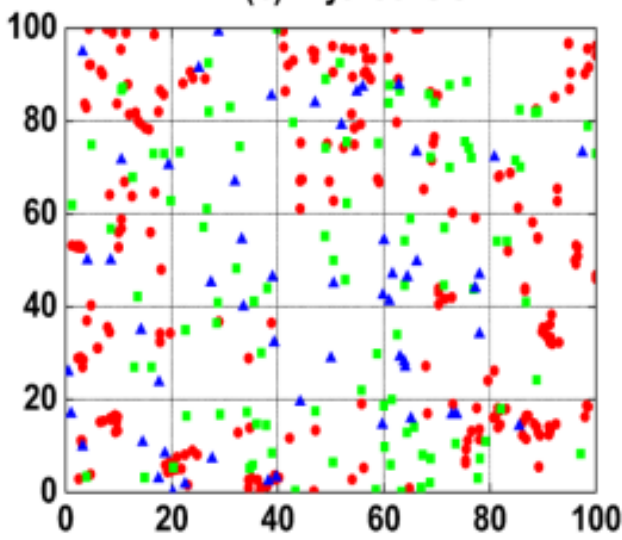

(d) T. amurensis

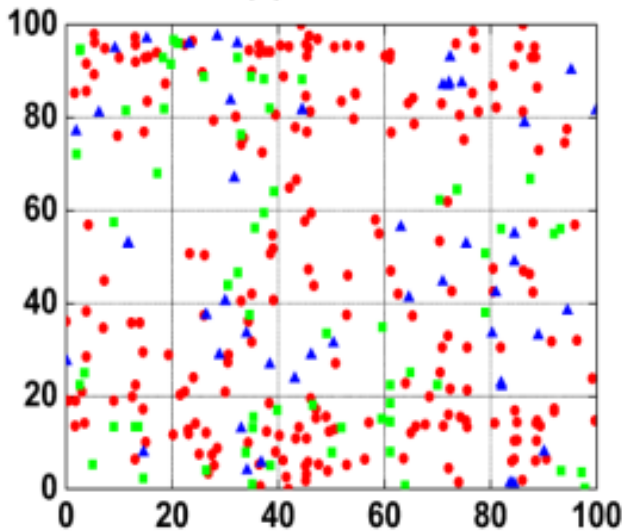

Figure 1. Spatial patterns of the dominant tree species in different height classes. $\bullet$, juvenile height class (height $<5 \mathrm{~m}$ ); $\backsim$, lower height class $(5-10 \mathrm{~m}$ ); and $\mathbf{\Delta}$, upper height class (height $>10 \mathrm{~m}$ )

The spatial point-pattern statistics of the dominant tree species in the different vertical layers are presented in Table 3. According to univariate statistical procedures, the spatial pattern of a single species was analysed in the different tree-height layers. For example, the distribution of Tilia (A) was clustered at scales of $0-1 \mathrm{~m}$, but the distributions were random at coarse scales. Tilia (J) was aggregated, with successively regular distributions at scales of $0-2 \mathrm{~m}$ and 7-15 $\mathrm{m}$. A similar but weaker trend emerged in Tilia (U) at scales of $0 \mathrm{~m}$ and 3-5 m, whereas Tilia (L) were randomly distributed at all scales. The distributions of Pinus were uniform among the various 
tree-height layers and were primarily random at all scales, except for Pinus (J), which was aggregated at a scale of $0-1 \mathrm{~m}$. The spatial distributions of Abies (A) and Abies (J) were both clustered at a scale of $0-4 \mathrm{~m}$ but were regularly distributed at 7-12 $\mathrm{m}$ and 7-14 m, respectively. Abies (L) and Abies (U) were regularly distributed at 6-10 $\mathrm{m}$ and 7-8 m, respectively. Picea (A) and Picea (J) had the same trends as Abies (L) and Abies (U) (clustered at 0-2 $\mathrm{m}$ and regular at 5-10 $\mathrm{m}$ and 5-11 m). Picea (L) and Picea (U) showed identical distributions at all scales.

Table 3. Spatial point patterns of the four dominant tree species in four height classes

\begin{tabular}{|c|c|c|c|c|c|c|c|c|c|c|c|c|c|c|c|c|c|c|}
\hline \multirow[t]{2}{*}{ Species } & \multicolumn{18}{|c|}{ Scale (m) } \\
\hline & 0 & 1 & 2 & 3 & 4 & 5 & 6 & 7 & 8 & 9 & & 10 & 11 & 12 & 13 & 14 & 15 & $16-20$ \\
\hline Tilia (A) & + & + & $\mathrm{r}$ & $\mathrm{r}$ & $\mathrm{r}$ & & $\mathrm{r}$ & $\mathrm{r}$ & $\mathrm{r}$ & & $\mathrm{r}$ & $\mathrm{r}$ & $\mathrm{r}$ & $\mathrm{r}$ & $\mathrm{r}$ & $\mathrm{r}$ & $\mathrm{r}$ & $\mathrm{r}$ \\
\hline Tilia $(\mathrm{J})$ & + & + & + & $\mathrm{r}$ & $\mathrm{r}$ & & $\mathrm{r}$ & - & - & & - & - & - & - & - & $\mathrm{r}$ & - & $\mathrm{r}$ \\
\hline Tilia (L) & $\mathrm{r}$ & $\mathrm{r}$ & $\mathrm{r}$ & $\mathrm{r}$ & $\mathrm{r}$ & & r & $\mathrm{r}$ & r & & $\mathrm{r}$ & $\mathrm{r}$ & $\mathrm{r}$ & $\mathrm{r}$ & $\mathrm{r}$ & $\mathrm{r}$ & $\mathrm{r}$ & $\mathrm{r}$ \\
\hline Tilia (U) & + & $\mathrm{r}$ & $\mathrm{r}$ & - & - & & r & $\mathrm{r}$ & $\mathrm{r}$ & & $\mathrm{r}$ & $\mathrm{r}$ & $\mathrm{r}$ & $\mathrm{r}$ & $\mathrm{r}$ & $\mathrm{r}$ & $\mathrm{r}$ & $\mathrm{r}$ \\
\hline Pinus (A) & $r$ & $\mathrm{r}$ & $\mathrm{r}$ & $\mathrm{r}$ & $r$ & & $\mathrm{r}$ & r & r & & $r$ & $r$ & $\mathrm{r}$ & $r$ & $\mathrm{r}$ & $\mathrm{r}$ & $\mathrm{r}$ & $\mathrm{r}$ \\
\hline Pinus (J) & + & + & $\mathrm{r}$ & $\mathrm{r}$ & $\mathrm{r}$ & & r & $\mathrm{r}$ & $\mathrm{r}$ & & $\mathrm{r}$ & $\mathrm{r}$ & $\mathrm{r}$ & $\mathrm{r}$ & $\mathrm{r}$ & $\mathrm{r}$ & $\mathrm{r}$ & $\mathrm{r}$ \\
\hline Pinus (L) & $\mathrm{r}$ & $r$ & r & $\mathrm{r}$ & $r$ & & r & $\mathrm{r}$ & r & & $r$ & $r$ & $r$ & $r$ & $\mathrm{r}$ & $\mathrm{r}$ & $\mathrm{r}$ & $\mathrm{r}$ \\
\hline Pinus (U) & $\mathrm{r}$ & $\mathrm{r}$ & $\mathrm{r}$ & $\mathrm{r}$ & $\mathrm{r}$ & & r & r & r & & $\mathrm{r}$ & $r$ & $\mathrm{r}$ & $\mathrm{r}$ & $\mathrm{r}$ & $\mathrm{r}$ & $\mathrm{r}$ & $\mathrm{r}$ \\
\hline Abies (A) & + & + & + & + & + & & r & - & - & & - & - & - & $-r$ & $\mathrm{r}$ & $\mathrm{r}$ & $\mathrm{r}$ & $\mathrm{r}$ \\
\hline Abies (J) & + & + & + & + & + & & $\mathrm{r}$ & - & - & & - & - & - & - & - & - & $\mathrm{r}$ & $\mathrm{r}$ \\
\hline Abies (L) & $\mathrm{r}$ & $\mathrm{r}$ & $\mathrm{r}$ & $\mathrm{r}$ & $\mathrm{r}$ & & - & - & r & & - & - & $\mathrm{r}$ & $\mathrm{r}$ & $\mathrm{r}$ & $\mathrm{r}$ & $\mathrm{r}$ & $\mathrm{r}$ \\
\hline Abies (U) & $\mathrm{r}$ & $\mathrm{r}$ & $\mathrm{r}$ & $\mathrm{r}$ & $\mathrm{r}$ & & r & - & - & & $\mathrm{r}$ & $\mathrm{r}$ & $\mathrm{r}$ & $\mathrm{r}$ & $\mathrm{r}$ & $\mathrm{r}$ & $\mathrm{r}$ & $\mathrm{r}$ \\
\hline Picea (A) & + & + & + & $\mathrm{r}$ & $\mathrm{r}$ & & - & - & - & & - & - & $\mathrm{r}$ & $\mathrm{r}$ & $\mathrm{r}$ & $\mathrm{r}$ & $\mathrm{r}$ & $\mathrm{r}$ \\
\hline Picea $(\mathrm{J})$ & + & + & + & $\mathrm{r}$ & $\mathrm{r}$ & & - & - & - & & - & - & - & $\mathrm{r}$ & $\mathrm{r}$ & $\mathrm{r}$ & $\mathrm{r}$ & $\mathrm{r}(+)$ \\
\hline Picea (L) & $\mathrm{r}$ & $\mathrm{r}$ & $\mathrm{r}$ & $\mathrm{r}$ & $\mathrm{r}$ & & $\mathrm{r}$ & $\mathrm{r}$ & $\mathrm{r}$ & & $\mathrm{r}$ & $\mathrm{r}$ & $\mathrm{r}$ & $\mathrm{r}$ & $\mathrm{r}$ & $\mathrm{r}$ & $\mathrm{r}$ & $\mathrm{r}$ \\
\hline Picea (U) & $r$ & $\mathrm{r}$ & $\mathrm{r}$ & $\mathrm{r}$ & $\mathrm{r}$ & & $\mathrm{r}$ & $\mathrm{r}$ & $\mathrm{r}$ & & $\mathrm{r}$ & $\mathrm{r}$ & $\mathrm{r}$ & $\mathrm{r}$ & $\mathrm{r}$ & $\mathrm{r}$ & $\mathrm{r}$ & $\mathrm{r}$ \\
\hline
\end{tabular}

+, clustered pattern; -, regular pattern; r, random pattern; + (r) more clustered pattern points than random patterns; $r(+)$, more random pattern points than clustered patterns; - $(r)$, more regular pattern points than random patterns; and r (-), more random pattern points than regular patterns

\section{Intra- and inter-specific spatial associations of dominant tree species in juvenile and upper layers (juvenile layer vs. upper layer trees)}

The spatial associations between the juvenile (J) and upper (U) layer trees varied by scale (Fig. 2). The pairs of the four species were positively correlated at small spatial scales only. At larger scale intervals, neutral or negative associations were found. For example, Tilia (J) and Abies (J) were positively associated with Abies (U) at scales of 5-6 $\mathrm{m}$ and $18-20 \mathrm{~m}$, and the associations were neutral at other scales. A positive association was found for Pinus (J) with Tilia (U) at a scale of 5-12 m. Abies (J) and Picea (J) showed similar interrelations with Tilia (U): (1) slight positive associations at scales of 5-7 m and 12-14 m; and (2) negative associations at scales of 7-8 m, 11-12 
$\mathrm{m}$, and 17-20 m. The two species pairs, Tilia (J) vs. Picea (U) and Pinus (J) vs. Pinus (U), were significantly and negatively associated at most scales $(0-10 \mathrm{~m}$ and $0-11 \mathrm{~m})$. The other species pairs were spatially independent at all scale intervals.
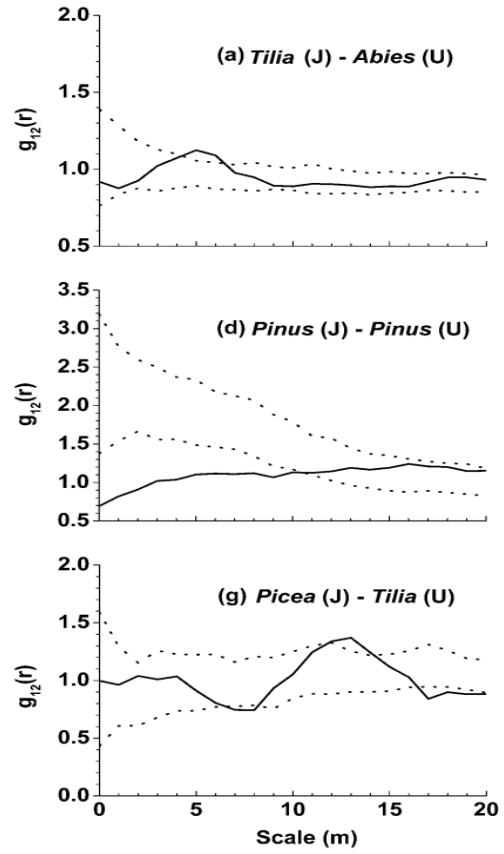

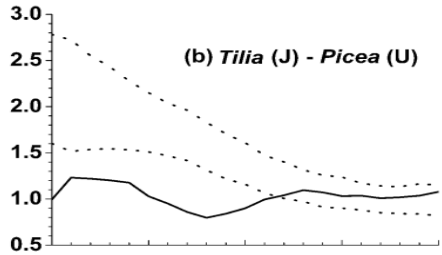

(e) Abies (J) - Tilia (U)
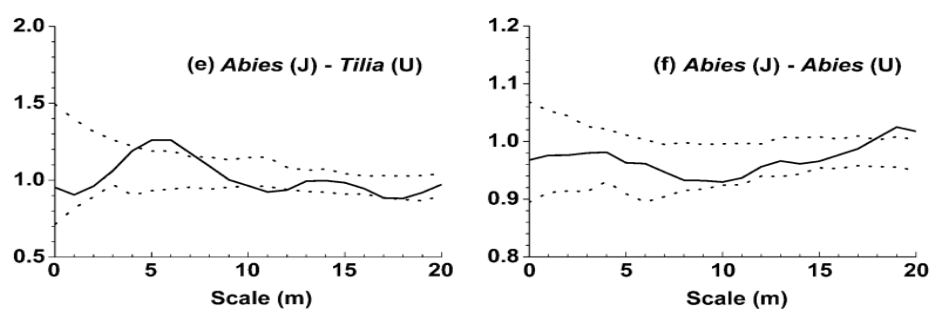

Figure 2. Spatial associations in the juvenile and upper height classes. Solid black lines refer to ring statistics $g(r)$; dashed lines indicate the upper and lower limits of the $99 \%$ confidence envelopes. Heterogeneous Poisson null model was used as the null model. Ring width of the pair correlation function was $4 \mathrm{~m}$. For a concise figure, the species pairs showed spatial independent in all scale intervals was not included (similarly hereinafter). J: juvenile height class; U: upper height class.

\section{Intra- and inter-specific spatial associations of dominant tree species in lower and upper layers (lower layer vs. upper layer trees)}

The spatial associations between the lower (L) height class and the upper (U) height class in various vertical layers are depicted in Fig. 3. The four species pairs had different spatial associations with other species pairs. Weak positive and strong neutral associations were shown in two species pairs, Abies (L) vs. Tilia (U) and Picea (L) vs. Picea (U), which were positively associated at scales of $0-1 \mathrm{~m}$ and 1-2 $\mathrm{m}$, respectively. In the species pair of Tilia (L) vs. Tilia (U), weak negative associations were observed at $4-5 \mathrm{~m}$ and $15 \mathrm{~m}$ scales, but the pair was spatially independent at other scales. However, as with the species pair of Pinus (J) vs. Pinus (U), Pinus in the lower tree-height layer was negatively associated with Pinus (U) at the $0-15 \mathrm{~m}$ scale, with neutral associations at other scales. Otherwise, the species pairs were spatially independent at all scale intervals. 

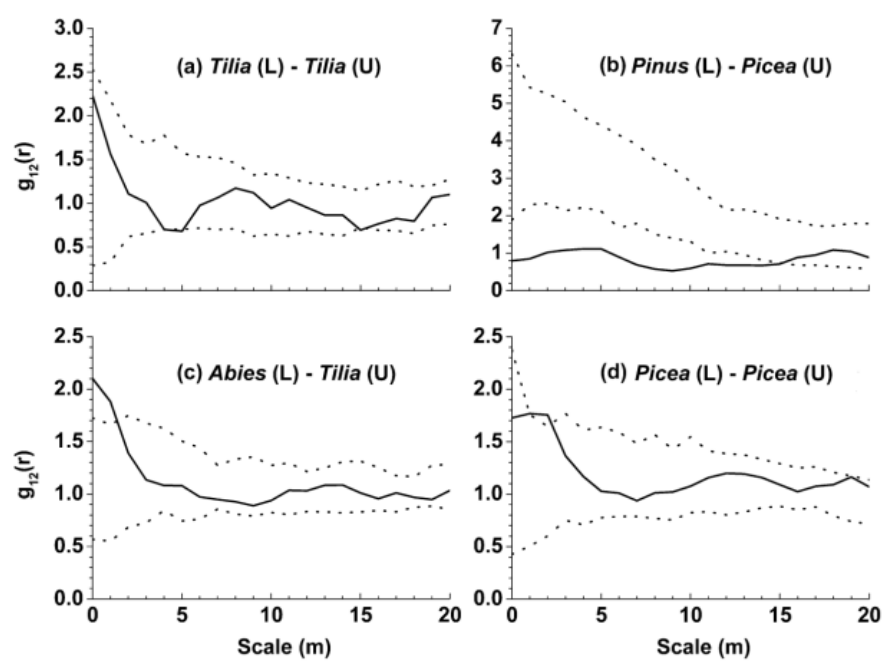

Figure 3. Spatial associations in the lower and upper height classes. Solid black lines refer to ring statistics $g(r)$; dashed lines indicate the upper and lower limits of the $99 \%$ confidence envelopes. Heterogeneous Poisson null model was used as the null model. Ring width of the pair correlation function was $4 \mathrm{~m}$. L: lower height class; $U$ : upper height class

\section{Discussion}

The spatial relationships among patterns, processes and scales are a major topic in ecology (Yuan et al., 2011; Cerrillo et al., 2013). In our study, we confirmed that spatial patterns and associations were closely related to spatial scales in a mixed coniferous-broadleaf forest and that habitat heterogeneity, limited seed dispersal and inter-specific competition might be the most important factors.

Species patterns of distribution are closely related to scale and vertical height layers (Hao et al., 2007). The distributions of the four dominant tree species (except Pinus) were clustered at fine scales, and the trees became less clustered with an increase in tree height. These findings were consistent with a previous study in which the degree of clustering was inversely proportional to tree-height layers (Condit et al., 2000). This phenomenon might be explained by the environmental heterogeneity (Harms et al., 2000; Queenborough et al., 2007). However, limited seed dispersal or biological characteristics of seeds of specific species might also explain the aggregated distributions of the dominant trees at small scales (Grubb, 1977). For example, cones of coniferous trees are large and heavy; thus, the cones do not disperse far. The seedlings and saplings from these seeds inevitably form aggregated distributions after germination (Seidler and Plotkin, 2006; Tamme et al., 2010; Lin et al., 2011). With Tilia trees, seedlings are typically abundant near the mother tree because of root sprouting (Zhang et al., 2011). At greater scales, regular distributions were observed in at particular scale intervals, which might be caused by a difference in the number of tree species or by spatial factors (e.g., disturbance or death) of associated species (Hou and Han, 1997). Additionally, some studies suggest that spatial patterns become more regular because of 
the competitive thinning process (Condit et al., 2000; Duncan, 1991; Haase et al., 1996). However, these results are not generalizable (Li et al., 2009).

The distributions of trees in the upper height class were significantly more random or regular than trees of juvenile or lower height classes; therefore, adult trees in the upper height class require more resources (Boyden et al., 2005; Druckenbrod et al., 2005; Quesada et al., 2009). Because limited resources could not meet the demands of all trees, "self-thinning" was likely triggered; this process caused the distributions to become increasingly random and regular $(\mathrm{Li}, 2010)$. We concluded that the results were consistent with those of other studies on spatial patterns (Li et al., 2009; Zhu et al., 2010).

In comparing the relationships of species' spatial associations among the different size classes, we found no significant relationship for most species pairs. However, for several species pairs, slight positive associations were detected at small-scale intervals. For example, the species pairs of Pinus (J) vs. Tilia (U), Abies (J) vs. Tilia (U), Abies $(\mathrm{L})$ vs. Tilia $(\mathrm{U})$, and Picea $(\mathrm{J})$ vs. Tilia $(\mathrm{U})$ showed positive associations at small scales. These observations might be caused by shade-tolerant characteristics of congeners, with upper-layer trees allowing for suitable light conditions for tree survival, establishment, and growth (Hao et al., 2007; Zhang et al., 2007). According to Helmus et al. (2007), similar habitat requirements might lead to positive associations. Additionally, the trend in aggregation between coniferous and broadleaf trees was due to the varying niches of coniferous and broadleaf trees, which fully use the available resource space, although habitat heterogeneity had different effects on the niche breadth (Potts et al., 2004; Riginos et al., 2005; Ali et al., 2010). Furthermore, spatially independent and slightly negative associations were observed at intermediate scales for Abies (J) vs. Tilia (U) and Picea (J) vs. Tilia (U), respectively; therefore, inter-specific competition might also occur under the upper tree canopy (Zhang et al., 2010). The Janzen-Connell theory explains high rates of mortality near mature trees, which might also partly contribute to the present associations (Matthesius et al., 2011; Steinitz et al., 2011).

The species pairs of Pinus (J) vs. Pinus (U), Tilia (J) vs. Picea (U), and Pinus (L) vs. Picea (U) had significant negative associations at large scales. Pinecones (e.g., Pinus and Abies) were harvested on the spot owing to their economic value; this adverse anthropogenic interference prevented recruitment of understory trees(Zhao et al., 2012). Nevertheless, Tilia (J) and Pinus (L) were negatively associated with Picea (U) at larger scales, suggesting that habitat heterogeneity might occur (e.g., topography, soil nutrients, and heterogeneous distribution of light) (Harms et al., 2000; Zhang et al., 2010).

\section{Conclusion}

Our major aim was to understand the spatial reciprocity among different tree-height classes of dominant species in a mixed coniferous-broadleaf forest. We reached the following conclusions: (1) Habitat heterogeneity, limited seed dispersal and inter-specific competition might be the most important factors that influence species spatial patterns and associations; and (2) Suitable conditions (such as light) are conducive for juvenile (sapling) growth, and adverse anthropogenic interference reduces 
the number of juveniles (saplings) under the canopies of intra- or inter-species adults. Therefore, artificial regeneration by planting juveniles under adult trees is an option. Artificial regeneration is expensive; however, it can establish particular species combinations or special spatial arrangements. The spatial associations and patterns reflected the coexistence and co-evolution among the dominant tree species. These results provided new insights into the development of reforestation techniques for mixed forests in northeastern China. Furthermore, in future studies, it will be necessary to evaluate the environmental and site factors (e.g., light, soil, and water) of tree stands.

Acknowledgements. This study was supported by the project of science and technology innovation of Shanxi agricultural university in China (Grant No. 2015YJ17). The author also thanks the editor and all anonymous reviewers for their constructive suggestions.

\section{REFERENCES}

[1] Ali, G.A., Roy, A.G., Legendre, P. (2010): Spatial relationships between soil moisture patterns and topographic variables at multiple scales in a humid temperate forested catchment. - Water Resour. Res. 46: 1-17.

[2] Boyden, S., Binkley, D., Shepperd, W. (2005): Spatial and temporal patterns in structure, regeneration, and mortality of an old-growth ponderosa pine forest in the Colorado Front Range. - Forest Ecol. Manag. 219(1): 43-55.

[3] Brokaw, N., Busing, R.T. (2000): Niche versus chance and tree diversity in forest gaps. Trends Ecol. Evol. 15: 183-188.

[4] Cerrillo, R.M.N., Manzanedo, R.D., Bohorque, J., Sánchez, R., Sánchez, J., Miguel, D.S., Solano, D., Qarro, M., Griffith, D., Palacios, G. (2013): Structure and spatio-temporal dynamics of cedar forests along a management gradient in the Middle Atlas, Morocco. Forest Ecol. Manag. 289: 341-353.

[5] Chen, J., Bradshaw, G.A. (1999): Forest structure in space: a case study of an old growth spruce-fir forest in Changbaishan Natural Reserve, PR China. - Forest Ecol. Manag. 120: 219-233.

[6] Condit, R., Ashton, P.S., Baker, P., Bunyavejchewin, S., Gunatilleke, S., Gunatilleke, N., Hubbell, S.P., Foster, R.B., Itoh, A., LaFrankie, J.V., Lee, H.S., Losos, E., Manokaran, N., Sukumar, R., Yamakura, T. (2000): Spatial patterns in the distribution of tropical tree species. - Sci. 288: 1414-1418.

[7] Druckenbrod, D.L., Shugart, H.H., Davies, I. (2005): Spatial pattern and process in forest stands within the Virginia piedmont. - J. Veg. Sci. 16: 37-48.

[8] Duncan R.P. (1991): Competition and the coexistence of species in a mixed podocarp stand. - J. Ecol. 79: 1073-1084.

[9] Fajardo, A., Goodburn, J.M., Graham, J. (2006): Spatial patterns of regeneration in managed uneven-aged ponderosa pine Douglas-fir forests of Western Montana, USA. Forest Ecol. Manag. 223: 255-266.

[10] Feeley, K.J., Davies, S.J., Perez, R., Hubbell, S.P., Foster, R.B. (2011): Directional changes in the species composition of a tropical forest. - Ecology 92: 871-882.

[11] Gagnon, J.L., Jokela, E.J., Moser, W.K., Huber, D.A. (2003): Dynamics of artificial regeneration in gaps within a longleaf pine flatwoods ecosystem. - Forest Ecol. Manag. 172: 133-144.

[12] Garbarino, M., Weisberg, P.J., Motta, R. (2009): Interacting effects of physical environment and anthropogenic disturbances on the structure of European larch (Larix 
decidua Mill.) forests. - Forest Ecol. Manag. 257: 1794-1802.

[13] Gonzalez-Rodriguez, V., Navarro-Cerrillo, R.M., Villar, R. (2011): Artificial regeneration with Quercus ilex L. and Quercus suber L. by direct seeding and planting in southern Spain. Ann. - Forest Sci. 68: 637-646.

[14] Gourlet-Fleury, S., Beina, D., Fayolle, A., Ouedraogo, D.Y., Mortier, F., Benedet, F., Closset-Kopp, D., Decocq, G. (2013): Silvicultural disturbance has little impact on tree species diversity in a Central African moist forest. - Forest Ecol. Manag. 304: 322-332.

[15] Grubb, P.J. (1977): The maintenance of species-richness in plant communities: the importance of the regeneration niche. - Biol. Rev. 52: 45.

[16] Haase P., Pugnaire F.I., Clark S., Incoll L. (1996): Spatial patterns in a two-tiered semi-arid shrubland in southeastern Spain. - J. Veg. Sci. (7): 527-534.

[17] Hao, Z.Q., Zhang, J., Song, B., Ye, J., Li, B.H. (2007): Vertical structure and spatial associations of dominant tree species in an old-growth temperate forest. - Forest Ecol. Manag. 252: 1-11.

[18] Harms, K.E., Wright, S.J., Calderon, O., Hernandez, A., Herre, E.A. (2000): Pervasive density-dependent recruitment enhances seedling diversity in a tropical forest. - Nature 404: 493-495.

[19] Helmus M.R., Savage K., Diebel M.W., Maxted J.T., Ives A.R. (2007): Separating the determinants of phylogenetic community structure. - Ecol. Lett. (10): 917-925

[20] Hou, X.Y., Han, J.X. (1997): Simulation Analysis of Spatial Patterns of Main Secies in the Korean-pine Broadleaved Forests in Changbai Mountain. - Acte Phytoecologica Sinica. 21: 242-249.

[21] Lei, X.D., Lu, Y.C., Peng, C.H., Zhang, X.P., Chang, J., Hong, L.X. (2007): Growth and structure development of semi-natural larch-spruce-fir (Larix olgensis-Picea jezoensis-Abies nephrolepis) forests in northeast China: 12-year results after thinning. Forest Ecol. Manag. 240: 165-177.

[22] Li, H.D., Guan, D.X., Wang, A.Z., Wu, J.B., Jin, C.J., Shi, T.T. (2013): Characteristics of evaporation over broadleaved Korean pine forest in Changbai Mountains, Northeast China during snow cover period in winter. Chin. - J. of Appl. Ecol. 24: 1039-1046.

[23] Li, J. (2010): Forest Ecology. pp:218-219. - Higher Education Press, 2nd ed, Beijing.

[24] Li, L., Huang, Z.L., Ye, W.H., Cao, H.L., Wei, S.G., Wang, Z.G., Lian, J.Y., Sun, I.F., Ma, K.P., He, F.L. (2009): Spatial distributions of tree species in a subtropical forest of China. - Oikos. 118: 495-502.

[25] Lin, Y.C., Chang, L.W., Yang, K.C., Wang, H.H., Sun, I.F. (2011): Point patterns of tree distribution determined by habitat heterogeneity and dispersal limitation. - Oecologia. 165: 175-184.

[26] Lochhead, K.D., Comeau, P.G. (2012): Relationships between forest structure, understorey light and regeneration in complex Douglas-fir dominated stands in south-eastern British Columbia. - Forest Ecol. Manag. 284: 12-22.

[27] Lockhart, B.R., Keeland, B., Mccoy, J., Dean, T.J. (2003): Comparing regeneration techniques for afforesting previously farmed bottomland hardwood sites in the Lower Mississippi Alluvial Valley, USA. - Forestry. 76: 169-180.

[28] Matthesius, A., Chapman, H. and Kelly, D. (2011): Testing for janzen-connell effects in a west african montane forest. - Biotropica. 43: 77-83.

[29] Nguyen, H.H., Uria-Diez, J., Wiegand, K. (2016): Spatial distribution and association patterns in a tropical evergreen broad-leaved forest of north-central Vietnam. - J Veg Sci. 27(2): 318-327.

[30] Potts M.D., Davies S.J., Bossert W.H., Tan S., Supardi M.N.N. (2004): Habitat heterogeneity and niche structure of trees in two tropical rain forests. - Oecologia. (139): 446-453.

[31] Queenborough S.A., Burslem D.F.R.P., Garwood N.C., Valencia R. (2007): Habitat niche 
partitioning by 16 species of Myristicaceae in Amazonian Ecuador. - Plant Ecol. (192): 193-207.

[32] Quesada, M., Sanchez-Azofeifa, G.A., Alvarez-Anorve, M., Stoner, K.E., Avila-Cabadilla, L., Calvo-Alvarado, J., Castillo, A., Espirito-Santo, M.M., Fagundes, M., Fernandes, G.W., Gamon, J., Lopezaraiza-Mikel, M., Lawrence, D., Morellato, L.P.C., Powers, J.S., Neves, F.D., Rosas-Guerrero, V., Sayago, R., Sanchez-Montoya, G. (2009): Succession and management of tropical dry forests in the Americas: Review and new perspectives. - Forest Ecol. Manag. 258: 1014-1024.

[33] Riginos, C., Milton, S.J., Wiegand, T. (2005): Context-dependent interactions between adult shrubs and seedlings in a semi-arid shrubland. - J. Veg. Sci. 16: 331-340.

[34] Ripley, B.D. (1981): Spatial Statistics. pp: 252. - Wiley, New York.

[35] Saiz, H., Alados, C.L., Pueyo, Y. (2014): Plant-plant spatial association networks in gypsophilous communities: the influence of aridity and grazing and the role of gypsophytes in its structure. - Web Ecol. 14(1): 39.

[36] Salas, C., Lemay, V., Nunez, P., Pacheco, P., Espinosa, A. (2006): Spatial patterns in an old-growth Nothofagus obliqua forest in south-central Chile. - Forest Ecol. Manag. 231: 38-46.

[37] Schweitzer, C.J., Dey, D.C. (2011): Forest structure, composition, and tree diversity response to a gradient of regeneration harvests in the mid-Cumberland Plateau escarpment region, USA. Forest Ecol. - Manag. 262: 1729-1741.

[38] Seidler, T.G., Plotkin, J.B. (2006): Seed dispersal and spatial pattern in tropical trees. Plos Biol. 4: e344

[39] Steinitz, O., Troupin, D., Vendramin, G.G., Nathan, R. (2011): Genetic evidence for a Janzen-Connell recruitment pattern in reproductive offspring of Pinus halepensis trees. Mol. Ecol. (20): 4152-4164.

[40] Stoyan, D., Penttinen, A. (2000): Recent applications of point process methods in forestry statistics. - Stat Sci. 15: 61-78.

[41] Strimbu, B.M., Petritan, I.C., Montes, C., Biris, I.A. (2017): An assessment of the O-ring methodology using virgin stands of mixed European beech-Sessile oak. - Forest Ecol. Manag. 384: 378-388.

[42] Tamme, R., Hiiesalu, I., Laanisto, L., Szava Kovats, R., Partel, M. (2010): Environmental heterogeneity, species diversity and co-existence at different spatial scales. - J. Veg. Sci. (21): 796-801.

[43] Velázquez, E., Paine, C.E., May, F., Wiegand, T. (2015): Linking trait similarity to interspecific spatial associations in a moist tropical forest. - J Veg. Sci. 26(6): 1068-1079.

[44] Wagner, S., Collet, C., Madsen, P., Nakashizuka, T., Nyland, R.D., Sagheb-Talebi, K. (2010): Beech regeneration research: From ecological to silvicultural aspects. - Forest Ecol. Manag. 259: 2172-2182.

[45] Wiegand, T., Gunatilleke, S., Gunatilleke, N. (2007): Species associations in a heterogeneous Sri lankan dipterocarp forest. - Am. Nat. (170): E77-E95.

[46] Wiegand, T., Moloney, K.A. (2004): Rings, circles, and null-models for point pattern analysis in ecology. - Oikos 104: 209-229.

[47] Wiegand, T., Gunatilleke, S., Gunatilleke, N., Okuda, T. (2007): Analyzing the spatial structure of a Sri Lankan tree species with multiple scales of clustering. - Ecology. 88: 3088-3102.

[48] Yuan, Z.Q., Gazol, A., Wang, X.G., Lin, F., Ye, J., Bai, X.J., Li, B.H., Hao, Z.Q. (2011): Scale specific determinants of tree diversity in an old growth temperate forest in China. Basic Appl. Ecol. (12): 488-495.

[49] Zhang, J., Hao, Z.Q., Song, B., Ye, J., Li, B.H., Yao, X.L. (2007): Spatial distribution patterns and associations of Pinus koraiensis and Tilia amurensis in broad-leaved Korean pine mixed forest in Changbai Mountains. Chin. - J. Appl. Ecol. (18): 1681-1687. 
[50] Zhang, J., Song, B., Li, B.H., Ye, J., Wang, X.G., Hao, Z.Q. (2010): Spatial patterns and associations of six congeneric species in an old-growth temperate forest. - Acta Oecol. 36: 29-38.

[51] Zhang, J.T. (2004): Quantitative ecology. - Science Press, Beijing.

[52] Zhang, L.W., Mi, X.C., Shao, H.B., Ma, K.P. (2011): Strong plant-soil associations in a heterogeneous subtropical broad-leaved forest. - Plant Soil. 347: 211-220.

[53] Zhang, M. T., Kang, X. G., Meng, J. H., Zhang, L. X. (2015): Distribution patterns and associations of dominant tree species in a mixed coniferous-broadleaf forest in the Changbai Mountains.- J Mount Sci. 12(3): 659-670.

[54] Zhao, H.Y., Kang, X.G., Guo, Z.Q., Yang, H., Xu, M. (2012): Species Interactions in Spruce-Fir Mixed Stands and Implications for Enrichment Planting in the Changbai Mountains, China. - Mt Res Dev. 32: 187-196.

[55] Zhu, Y., Mi, X.C., Ren, H.B., Ma, K.P. (2010): Density dependence is prevalent in a heterogeneous subtropical forest. -Oikos 119: 109-119. 